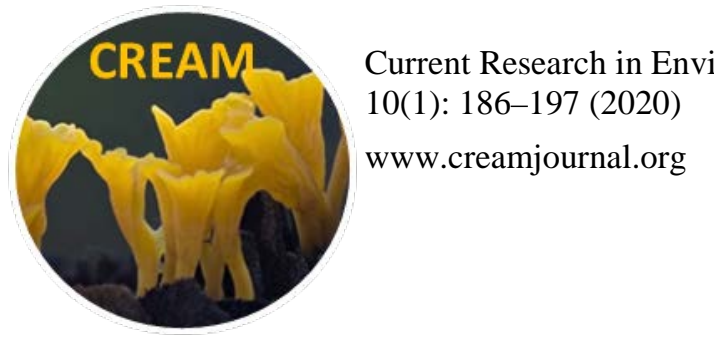

\title{
The hygrophoroid fungi (Basidiomycota, Agaricales, Hygrophoraceae) from Republic of São Tomé and Príncipe, West Africa
}

\section{Desjardin $\mathrm{DE}^{1}$ and Perry $\mathrm{BA}^{2}$}

${ }^{1}$ Department of Biology, San Francisco State University, 1600 Holloway Ave., San Francisco, California 94132, USA ${ }^{2}$ Department of Biological Sciences, California State University East Bay, 25800 Carlos Bee Blvd., Hayward, California 94542, USA

Desjardin DE, Perry BA 2020 - The hygrophoroid fungi (Basidiomycota, Agaricales, Hygrophoraceae) from Republic of São Tomé and Príncipe, West Africa. Current Research in Environmental \& Applied Mycology (Journal of Fungal Biology) 10(1), 186-197, Doi 10.5943/cream/10/1/19

\begin{abstract}
Five species of hygrophoroid fungi belonging to the genera Cuphophyllus and Hygrocybe are reported from the African island nation, Republic of São Tomé and Príncipe. These taxa represent two new species (C. laranja, H. macambrarensis), one undetermined taxon, and two new distributional reports. Comprehensive descriptions, line drawings, color photographs, and comparisons with allied taxa based on morphology and molecular sequence data (ITS) are provided.
\end{abstract}

Key words - Cuphophyllus - fungal diversity - Hygrocybe - mushrooms - Gulf of Guinea

\section{Introduction}

Scientists from the California Academy of Sciences and joined by mycologists from San Francisco State University visited the west African islands of São Tomé and Príncipe in April 2006 ( $2 \mathrm{wk}$ ) and April 2008 (3 wk) to document the diversity of plants, amphibians, marine invertebrates and macrofungi. This is the seventh in a series of papers focused on documenting the basidiomycetous macrofungi from the Republic (Cooper et al. 2018, Desjardin \& Perry 2009, 2015a, b, 2016, 2017).

Hygrophoroid fungi have a body form suggestive of members of the white-spored genera Hygrophorus, Hygrocybe and Cuphophyllus (Hesler \& Smith 1963). Other genera in the Hygrophoraceae, as circumscribed by Lodge et al. (2013), have not been reported or collected by us from São Tomé and Príncipe. Prior to the research published here, no hygrophoroid fungi have been reported from the Republic. Indeed, only limited reports of hygrophoroid fungi have been published from Africa (Beeli 1928, Heinemann 1963, Pegler 1977, van der Westhuizen \& Eicker 1994, Boertmann 1998). To illustrate the uncommonness of hygrophoroid fungi in São Tomé and Príncipe, in five weeks of collecting over two different expeditions, 5-6 hours per day sampling numerous different habitats, only six specimens were collected, representing the five species reported here.

\section{Materials \& Methods}




\section{Sampling and morphological study}

Fresh specimens were dried on a Nesco food dehydrator, packed in airtight plastic bags and hand carried back to the US. Macromorphological data were derived from fresh specimens, whereas micromorphological data were derived from dried specimens rehydrated in ethanol followed by distilled water, 3\% $\mathrm{KOH}$ or Melzer's reagent. Color terms and notations are those of Kornerup \& Wanscher (1978). Basidiospore statistics include: $\mathrm{x}_{\mathrm{m}}$, the arithmetic mean of the spore length by spore width ( \pm standard deviation) for $n$ spores measured in a single specimen; $x_{m r}$, the range of spore means, and $\mathrm{x}_{\mathrm{mm}}$, the mean of spore means $( \pm \mathrm{SD})$ when more than one specimen is available; Q, the quotient of spore length by spore width in any one spore, indicated as a range of variation in $\mathrm{n}$ spores measured; $\mathrm{Q}_{\mathrm{m}}$, the mean of $\mathrm{Q}$-values in a single specimen; $\mathrm{Q}_{\mathrm{mr}}$, the range of $\mathrm{Q}_{\mathrm{m}}$ values and $\mathrm{Q}_{\mathrm{mm}}$, the mean of $\mathrm{Q}_{\mathrm{m}}$ values where more than one specimen is available; $\mathrm{n}$, the number of spores measured per specimen; s, the number of specimens involved. All specimens are deposited in the H.D. Thiers Herbarium (SFSU) at San Francisco State University.

\section{DNA extraction, PCR and sequencing}

Total genomic DNA was extracted from dried material using the Extract-N-Amp Plant PCR Kit (Sigma-Aldrich, St. Louis, MO) following manufacturer instructions. PCR protocols followed those outlined in Perry et al. (2007). For most specimens reported, the nuclear ribosomal internal transcribed spacer region (ITS) was amplified using primers ITS1/ITS4 (Gardes \& Bruns 1993, White et al. 1990). Amplification products were cleaned using the Exo-SAPit kit (Affymetrix, Santa Clara, CA), and sent to Elim Biopharmaceuticals (Hayward, CA) for sequencing with the same primer pairs used for amplification.

\section{Sequence comparisons to aid in species delimitation}

Sequencing products were edited and assembled in Geneious 9.0 (Biomatters Ltd., Auckland, New Zealand), and aligned to the top ten BLASTn (Altschul et al. 1990) matches using the Geneious alignment tool with default settings. Alignments were used to calculate pairwise genetic distances in Geneious for entire aligned, overlapping sequence regions. All ITS sequences generated as part of this study have been deposited in GenBank (accessions MT117074 MT117077).

\section{Taxonomy}

Cuphophyllus pratensis (Fr.) Bon, Docums Mycol. 14(56): 10.1985 (1984).

Figs $1,2 \mathrm{a}-\mathrm{C}$

Basionym: Agaricus pratensis Fr., Observ. Mycol. (Havniae) 2: 116. 1818.

= Hygrophorus pratensis (Fr.) Fr., Anteckn. Sver. Ätl. Svamp.: 46. 1836.

= Camarophyllus pratensis (Fr.) P. Kumm., Führ. Pilzk. (Zerbst): 118. 1871.

= Hygrocybe pratensis (Fr.) Murrill, Mycologia 6(1): 2. 1914.

Pileus $20-55 \mathrm{~mm}$ diam, obtusely conical to campanulate, expanding to irregularly wavyplane, centrally depressed; margin incurved to decurved, undulate, cleft in age; surface dull, moist to dry, glabrous, sometimes rugulose, hygrophanous, orange to golden orange (5A-B6-8) when young, fading to light yellow (4A4) or cream (4A3) with moisture loss and in age. Context 2-3 mm thick, white to pale yellow or cream (3-4A2-3). Lamellae decurrent, distant with 2-3 series of lamellulae, broad (3-5 mm), cream (4A3). Stipe 25-45 × 3-9 mm, central to eccentric, terete or flattened, cylindrical or more commonly narrowed downward, hollow; surface dull, dry, glabrous, streaked, pale orangish white (5A3) to cream (4A3). Odor and taste indistinct.

Basidiospores 6.0-7.5 × 4.5-5.5 $\mu \mathrm{m}\left[\mathrm{x}_{\mathrm{m}}=6.7 \pm 0.41 \times 5.0 \pm 0.30 \mu \mathrm{m}, \mathrm{Q}=1.2-1.5, \mathrm{Qm}_{\mathrm{m}}=\right.$ $1.34 \pm 0.09, \mathrm{n}=20, \mathrm{~s}=1$ ], ovoid to broadly ellipsoid, smooth, hyaline, inamyloid, thin-walled. Basidia 48-60 × 6.0-8.3 $\mu \mathrm{m}$, clavate, hyaline, contents oily, 4-spored. Basidioles cylindrical to subclavate. Cheilocystidia absent. Pleurocystidia absent. Pileipellis a cutis of interwoven hyphae with repent to erect terminal cells; hyphae 3-8 $\mu \mathrm{m}$ diam, cylindrical, hyaline, inamyloid, nonincrusted, non-gelatinous, thin-walled to firm-walled $(<0.5 \mu \mathrm{m})$; terminal cells $52-120 \times 4.5-9.5$ 
$\mu \mathrm{m}$, cylindrical to fusoid, hyaline, thin-walled to firm-walled. Pileus trama interwoven; hyphae 3$11 \mu \mathrm{m}$ diam, cylindrical, hyaline, inamyloid, non-gelatinous, thin-walled. Lamellar trama interwoven with a narrow subparallel mediostratum; hyphae 3-6.5 (-8) mm diam, cylindrical, hyaline, inamyloid, non-gelatinous, thin-walled to thick-walled $(-0.5 \mu \mathrm{m})$. Stipitipellis a cutis. Clamp connections present.

Habitat and known distribution - Solitary to scattered in soil in secondary forest. Pantemperate.

Material examined - AFRICA. Príncipe, Dois Irmãos area, N0134.889', E07²5.548', elev. 100 m, 23 April 2008, coll. by D.E. Desjardin, DED 8312 (SFSU).

Notes - The Príncipe specimen is macro- and micromorphologically indistinguishable from Cuphophyllus pratensis specimens from Europe (Arnold 1990, Candusso 1997).

Due to the presence of numerous insertions/deletions in the ITS region, we were not able to successfully sequence this marker for collection DED 8312 and therefore have no pairwise genetic comparisons for this taxon.

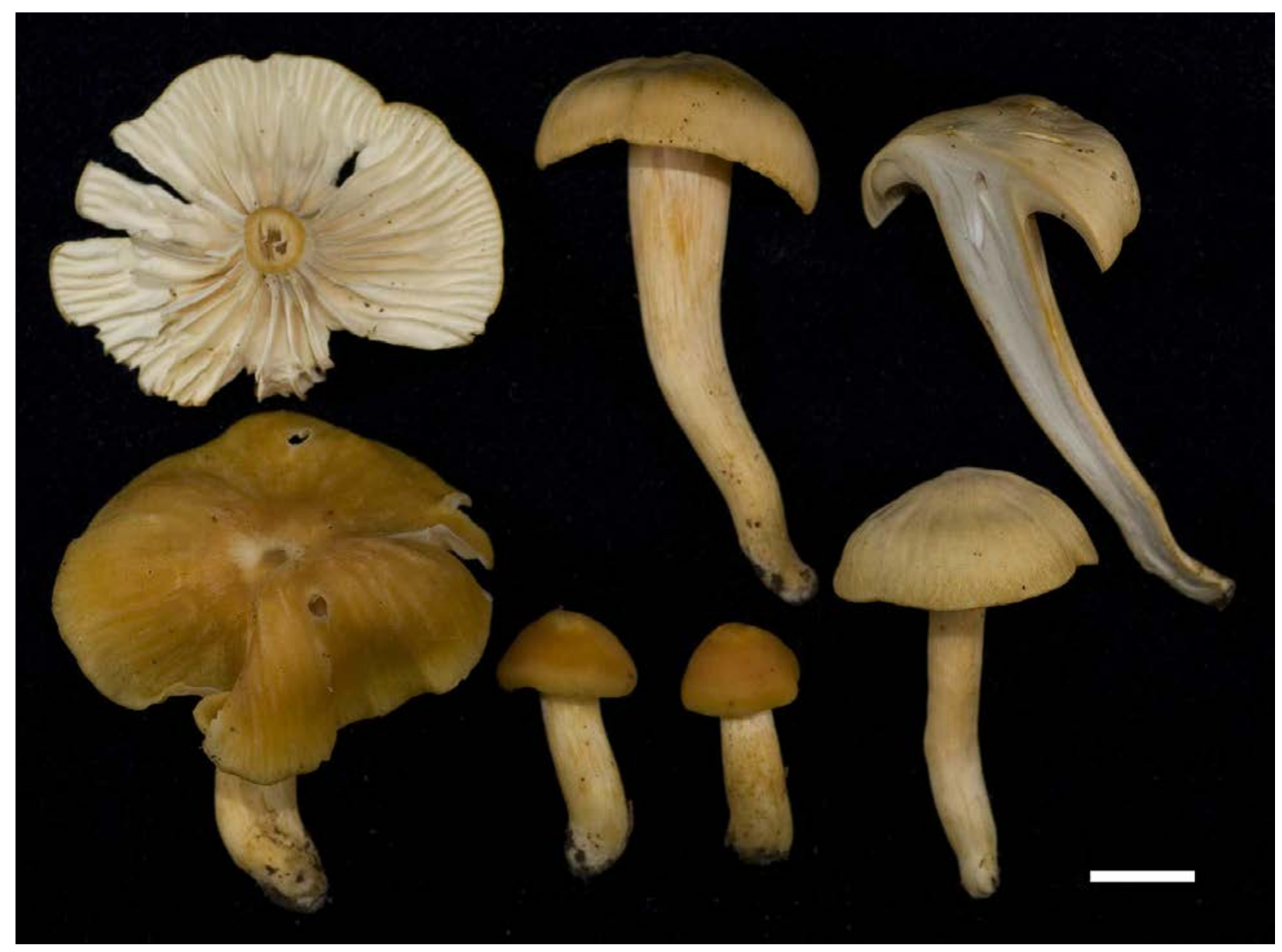

Fig. 1 - Basidiomes of Cuphophyllus pratensis (DED 8312). Scale bars $=10 \mathrm{~mm}$.

Cuphophyllus laranja Desjardin \& B.A. Perry, sp. nov.

Figs 2d-e, 3

Mycobank number: MB 834840

Holotype - AFRICA. São Tomé, Macambrara radio antenna area, N00¹6.557', E06 ${ }^{\circ} 36.326^{\prime}$, elev. 1300 m, 11 April 2008, coll. by D.E. Desjardin, DED 8202 (SFSU)

Etymology - laranja (Portuguese) $=$ orange, referring to the colour of the basidiomes.

Diagnosis - Pileus 4-15 (-25) mm diam, convex to campanulate or cuspidate, expanding to broadly convex or plano-convex in age, with or without a small narrow umbo or shallow central depression, short-striatulate; surface moist to dry, glabrous, hygrophanous, deep orange (5-6A7-8) when young, fading to orange (5A4-6) or orangish white (5A2-3) with moisture loss. Context 1-2 
mm thick, concolorous with surface. Lamellae adnate to subdecurrent, distant with 1-2 series of lamellulae, moderately broad (1-3 mm), deep orange (5-6A6-8), fading with age to orange (5A45). Stipe 10-28 × 1-3 mm, central, terete to compressed, cylindrical, hollow; surface dull, dry, glabrous, orange (5-6A4-7) overall, base with white mycelium. Odor and taste indistinct.

Basidiospores 6-7 × 3.5-4.5 $\mu \mathrm{m}\left[\mathrm{x}_{\mathrm{mr}}=6.3-6.4 \times 3.9-4.1 \mu \mathrm{m}, \mathrm{x}_{\mathrm{mm}}=6.35 \pm 0.02 \times 4.02 \pm\right.$ $0.18 \mu \mathrm{m}, \mathrm{Q}=1.3-1.8, \mathrm{Q}_{\mathrm{mr}}=1.54-1.63, \mathrm{Q}_{\mathrm{mm}}=1.59 \pm 0.06, \mathrm{n}=15-20, \mathrm{~s}=2$ ], ovoid to lacrymoid, smooth, hyaline, inamyloid, thin-walled. Basidia 22-36 × 6-7 $\mu \mathrm{m}$, clavate, hyaline, 4-spored. Basidioles subclavate. Cheilocystidia absent. Pleurocystidia absent. Pileipellis a cutis of repent hyphae 3.2-6.5 $\mu \mathrm{m}$ diam, non-diverticulate, smooth or incrusted, hyaline, inamyloid, nongelatinous; pileocystidia absent. Pileus trama interwoven, hyphae similar to those of pileipellis. Lamellar trama interwoven; hyphae 2-6 $\mu$ m diam, cylindrical, seldom slightly inflated, smooth or roughened, hyaline, inamyloid, non-gelatinous. Stipitipellis similar to the pileipellis. Clamp connections present.

Habitat and known distribution - Solitary to scattered in soil in montane native forest. Africa (São Tomé).

Material examined - AFRICA. São Tomé, Macambrara radio antenna area, N00 16.557 ', E06 36.326', elev. 1300 m, 11 April 2008, coll. by D.E. Desjardin, DED 8202 (Holotype, SFSU; MT117074); same location, 25 April 2008, coll. by D.E. Desjardin, DED 8330 (SFSU, MT117075).
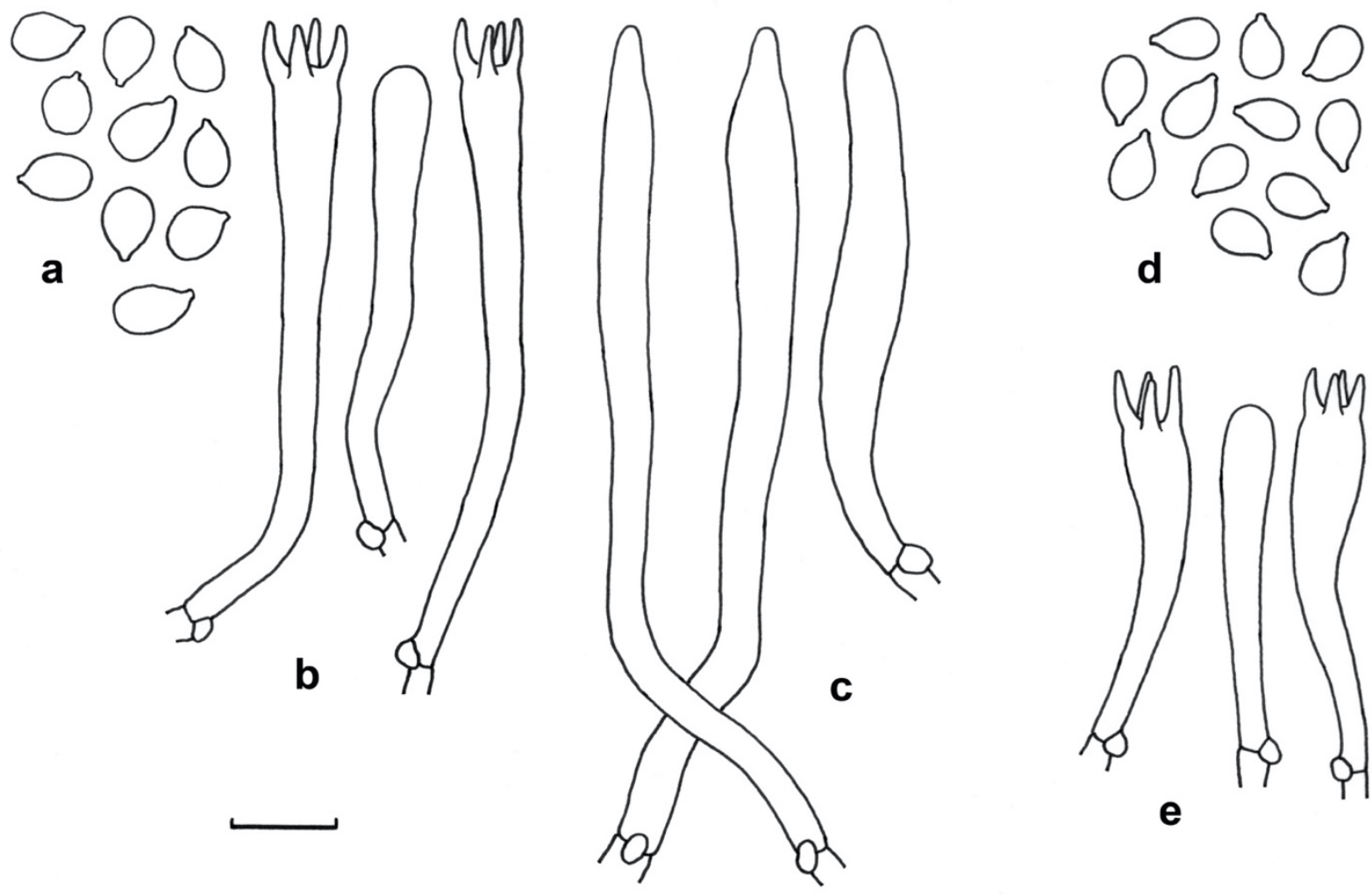

Fig. 2 - Micromorphological features of Cuphophyllus species. a-c Cuphophyllus pratensis (DED 8312). a Basidiospores. b Basidia and basidiole. c Pileipellis terminal cells. d-e C. laranja (Holotype, DED 8202). d Basidiospores. e Basidia and basidiole. Scale bars $=10 \mu \mathrm{m}$.

Notes - Cuphophyllus laranja is characterized by small basidiomes with deep orange, campanulate, non-viscid pileus, orange, subdecurrent lamellae, a gracile, orange stipe, interwoven hymenophoral trama of cylindrical hyphae 2-6 $\mu \mathrm{m}$ diam, ovoid to lacrymoid basidiospores $6-7 \times$ 3.5-4.5 $\mu \mathrm{m}$, no hymenial cystidia, a cutis-type pileipellis and stipitipellis of repent hyphae, 
abundant clamp connections, and growth in soil in montane native forest. The dry, campanulate pileus in combination with interwoven hymenophoral trama indicate placement in Cuphophyllus sect. Cuphophyllus. The deep orange basidiomes, more suggestive of a Hygrocybe, distinguish C. laranja from all other described members of sect. Cuphophyllus.

Pairwise comparisons of aligned, overlapping ITS sequences from both collections of $C$. laranja with the top ten BLASTn results indicate closest similarity (75.3-80.9\%) to seven sequences identified as Cuphophyllus pratensis (as Cuphophyllus, Camarophyllus or Hygrocybe; MK607482-Indiana, MK575237-Indiana, DQ486683-Massachusetts, MH558282-Tennessee, KF291057-Scotland, FM208874-Hungary, JF907767-Italy), and 75.7-77.1\% similarity with three uncultured fungus clones from Scotland (AF504858, AF504867) and North Carolina (AY969821). The morphological analyses reported here, in combination with the ITS sequences data indicate that the São Tomé specimens are unique and represent a new species.

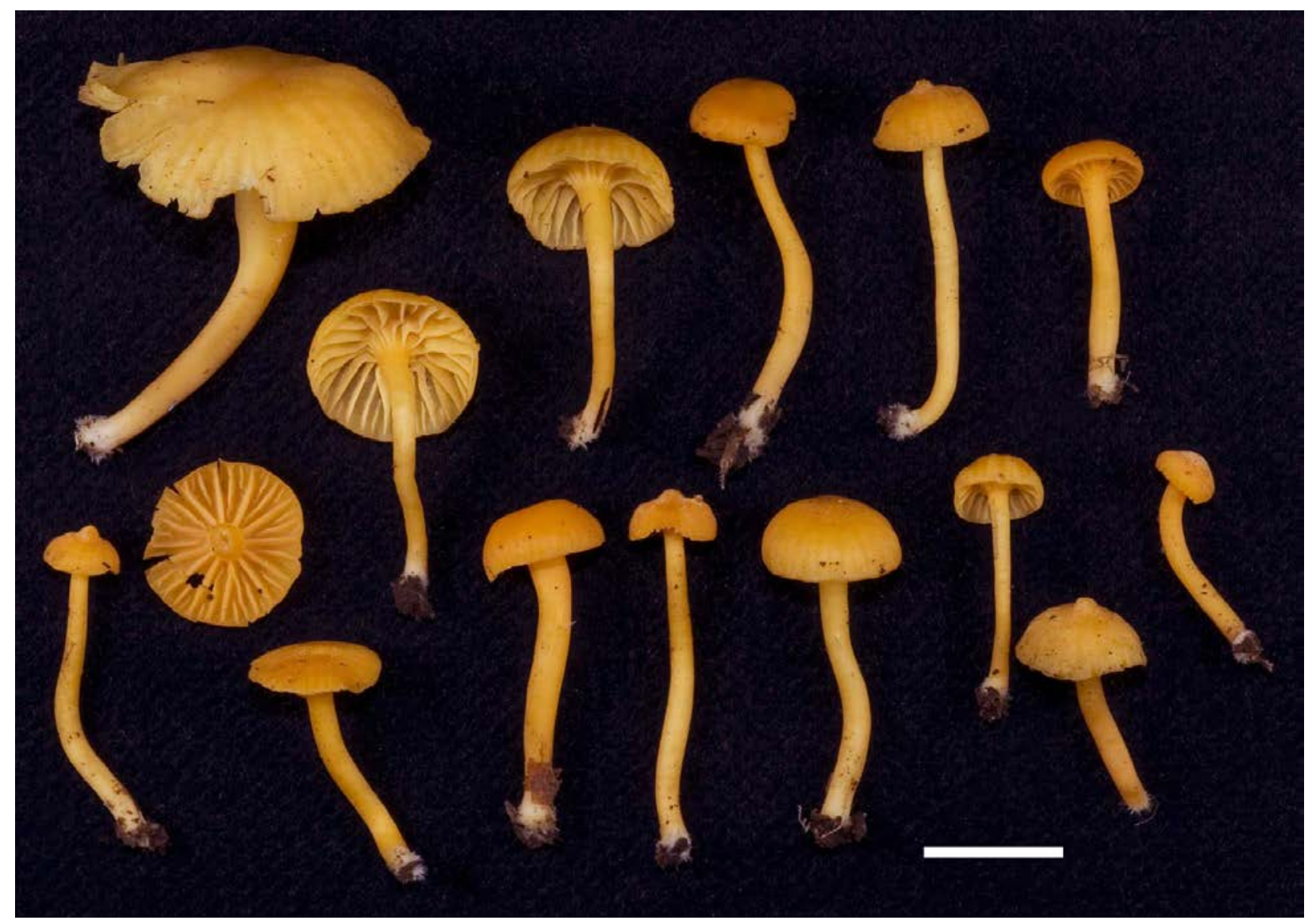

Fig. 3 - Basidiomes of Cuphophyllus laranja (Holotype, DED 8202). Scale bars $=10 \mathrm{~mm}$

Hygrocybe macambrarensis Desjardin \& B.A. Perry, sp. nov.

Figs 4, 5

Mycobank number: MB 834841

Holotype - AFRICA. São Tomé, Macambrara radio antenna area, N00o16.557', E06³6.326', elev. 1300 m, 11 April 2008, coll. by B.A. Perry and D.E. Desjardin, BAP 597 (SFSU). collected.

Etymology - honoring Macambrara radio antenna area, the site where the specimen was

Diagnosis - Pileus 7-45 mm diam, obtusely conical to campanulate, expanding to planocampanulate in age; margin decurved, becoming eroded, short pellucid-striate; surface moist to dry, smooth, glabrous, scarlet red (9-10A8) on the disc, fading to reddish orange (6-7A8) towards the margin. Lamellae ascending-adnate, with or without a short decurrent tooth, subdistant with 1-3 series of lamellulae, thick, waxy, margin slightly intervenose in mature basidiomes, white to pale yellowish white or cream (4A2-3). Stipe 22-75 × 1.5-5.5 mm, central, terete, cylindrical or with 
slightly enlarged base, hollow to stuffed; surface dull, dry, smooth, glabrous to canescent; apex yellow (3A4-6) to yellowish orange (4-5A7-8), centrally reddish orange (6-7A8), base yellowish orange (4-5A7-8) with scant white fibrils. Odor and taste indistinct.

Basidiospores dimorphic (relatively few observed): macrospores 9.6-12.5 × 5.6-7.0 $\mu \mathrm{m}\left[\mathrm{x}_{\mathrm{m}}\right.$ $\left.=11.2 \pm 1.07 \times 6.2 \pm 0.52 \mu \mathrm{m}, \mathrm{Q}=1.8-2.0, \mathrm{Q}_{\mathrm{m}}=1.83 \pm 0.18, \mathrm{n}=15, \mathrm{~s}=1\right]$; microspores 5.5-6.5 $\times 3.2-3.8 \mu \mathrm{m}\left[\mathrm{x}_{\mathrm{m}}=6.0 \pm 0.46 \times 3.5 \pm 0.25 \mu \mathrm{m}, \mathrm{Q}=1.4-1.9, \mathrm{Q}_{\mathrm{m}}=1.70 \pm 0.18, \mathrm{n}=10, \mathrm{~s}=1\right]$, smooth, hyaline, inamyloid, thin-walled. Macrobasidia 38-47 × 11.5-13 $\mu \mathrm{m}$, broadly clavate, 4spored, often with yellow granular contents, clamped. Microbasidia 22-30 × 5.5-8 $\mu \mathrm{m}$, clavate, 4spored, hyaline, clamped. Lamellar edge fertile. Cheilocystidia scattered, 32-40 × 5-9 $\mu \mathrm{m}$, cylindrical to clavate, hyaline. Pleurocystidia absent. Pileipellis a cutis of cylindrical hyphae 4.5-12 $\mu \mathrm{m}$ diam, non-gelatinous, smooth, pale yellow, inamyloid, thin-walled. Lamellar trama regular. Stipitipellis a cutis, similar to the pileipellis. Clamp connections present.

Habitat and known distribution - Scattered in soil in montane native forest. Africa (São Tomé).

Material examined - AFRICA. São Tomé, Macambrara radio antenna area, N00 16.557 ', E06 36.326', elev. 1300 m, 11 April 2008, coll. by B.A. Perry and D.E. Desjardin, BAP 597 (Holotype, SFSU; MT117076).

Notes - Hygrocybe macambrarensis is distinguished by a non-viscid, scarlet red to reddish orange, glabrous (neither furfuraceous nor squamulose), campanulate pileus (neither umbilicate nor perforate), white to pale yellowish white, adnate lamellae, a dry, reddish orange stipe, dimorphic basidia with rather short macrospores 9.6-12.5 × 5.6-7.0 $\mu \mathrm{m}$ and microspores 5.5-6.5 × 3.2-3.8 $\mu \mathrm{m}$, non-distinctive cutis-type pileipellis and stipitipellis, and growth in soil in montane native forest. The dimorphic basidia and basidiospores indicate placement in sect. Firmae.

Red taxa in sect. Firmae with relatively short macrospores in the range 10-13 $\times 6-7.5 \mu \mathrm{m}$ include: Hygrocybe trinitensis (Dennis) Pegler, from Trinidad, differs in forming umbilicate pilei, red lamellae, and larger microspores 7-9 × 4.5-5.5 $\mu \mathrm{m}$; H. siparia (Berk.) Singer, from Brazil, differs in umbilicate, furfuraceous to squamulose pilei with trichodermium-type pileipellis, and larger microspores 6.5-7 $\times 4.5-5 \mu \mathrm{m}$; $H$. occidentalis var. scarletina Pegler \& Fiard, from the Caribbean, differs in depressed and perforate pileus, orangish yellow to coral red lamellae, and larger microspores 6.5-8 × 3.5-5 $\mu \mathrm{m}$ (Pegler \& Fiard 1978, Lodge \& Pegler 1990). A number of red taxa in sect. Firmae have been described with larger macrospores in the range 12-16 $\mu \mathrm{m}$ long, and many also have depressed or umbilicate pilei: viz., $H$. purpurea (Beeli) Heinem. and $H$. emeticicolor Heinem. from the DR Congo (Heinemann 1963); H. miniatofirma S.A. Cantrell \& Lodge from Puerto Rico (Cantrell \& Lodge 2001); H. rubroalba Picciola, Battistin \& Vizzini from Brazil (Vizzini et al. 2015); and H. natarajanii Senthil. \& Kumaresan and H. manadukaensis Senthil., Kumaresan \& S.K. Singh from India (Senthilarasu et al. 2010a, 2010b). Hygrocybe batistae Singer, from the neotropics, shows many similarities but differs in having a pileipellis with diverticulate to coralloid hyphae and larger microspores, 6.3-7.3 $\times 4.2-5.2 \mu \mathrm{m}$ (Lodge \& Pegler 1990).

Pairwise comparisons of aligned, overlapping ITS sequences of $H$. macambrarensis with the top ten BLASTn results indicate closest similarity to the following taxa: 79.8\% similarity with $H$. griseobrunnea (KC914883) and 78.7\% with H. sparsifolia (KJ747390) from China; 79.1\% similarity with $H$. caespitosa (KF291104) from West Virginia, USA; 79.1\% similarity to a collection from Florida, USA identified as Hygrocybe sp. (MH211978); 78.7\% similarity to $H$. melleofusca from Puerto Rico (KF291154); 79.3-80.2\% similarity to four uncultured soil fungus clones from Minnesota, USA (DQ420689, DQ420690, DQ420693, DQ420703); and 79.1\% similarity to an uncultured Hygrocybe clone sequence (MG707526) isolated from Orchid roots in China. None of these named taxa belong in sect. Firmae. Of the ten species from sect. Firmae compared to $H$. macambrarensis in the preceding paragraph, only a single ITS sequence of $H$. rubroalba (NR155167) is available for comparison, which shows $68.6 \%$ similarity to $H$. macambrarensis. 


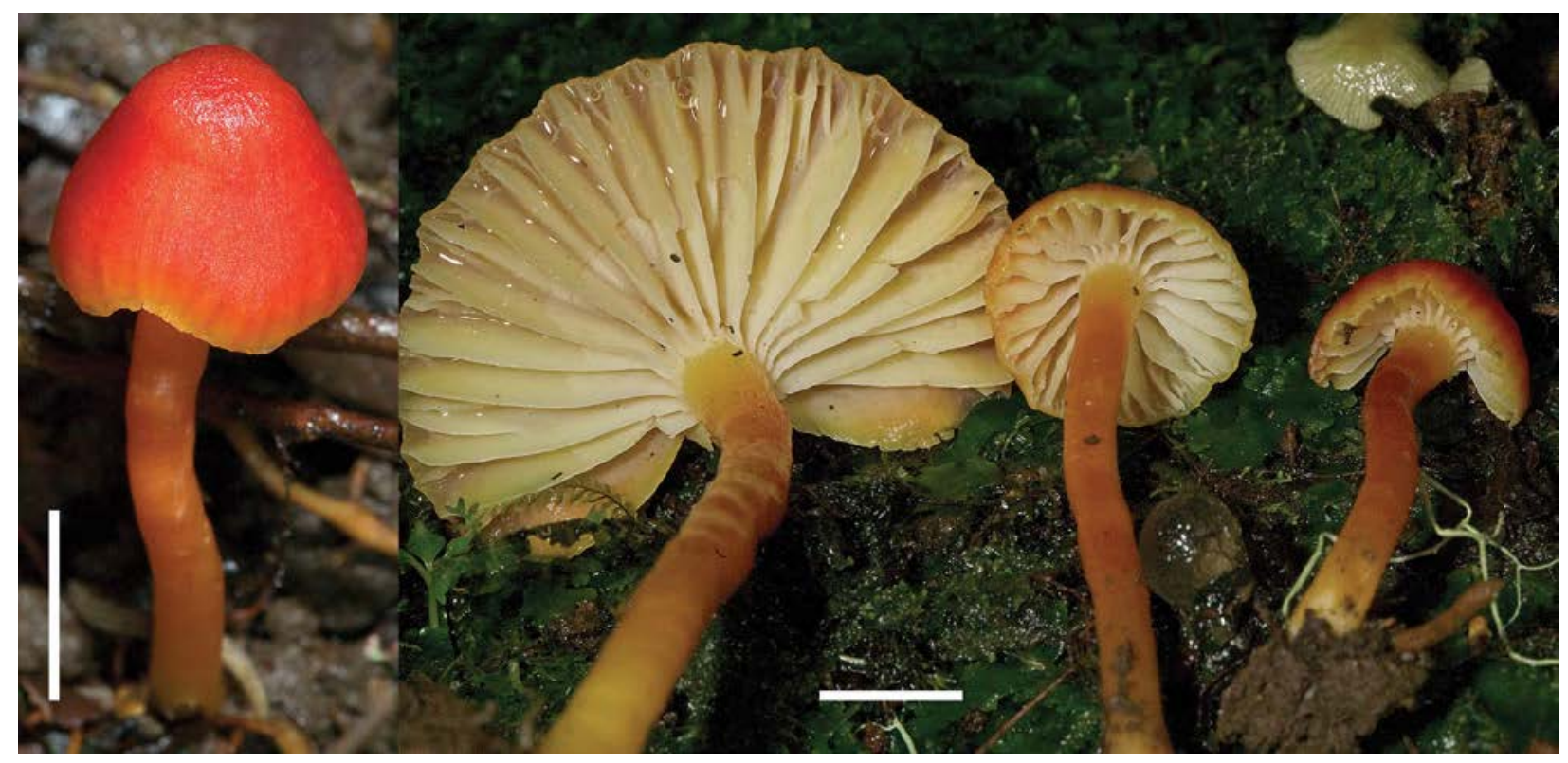

Fig. 4 - Basidiomes of Hygrocybe macambrarensis (Holotype, BAP 597). Scale bar $=10 \mathrm{~mm}$.
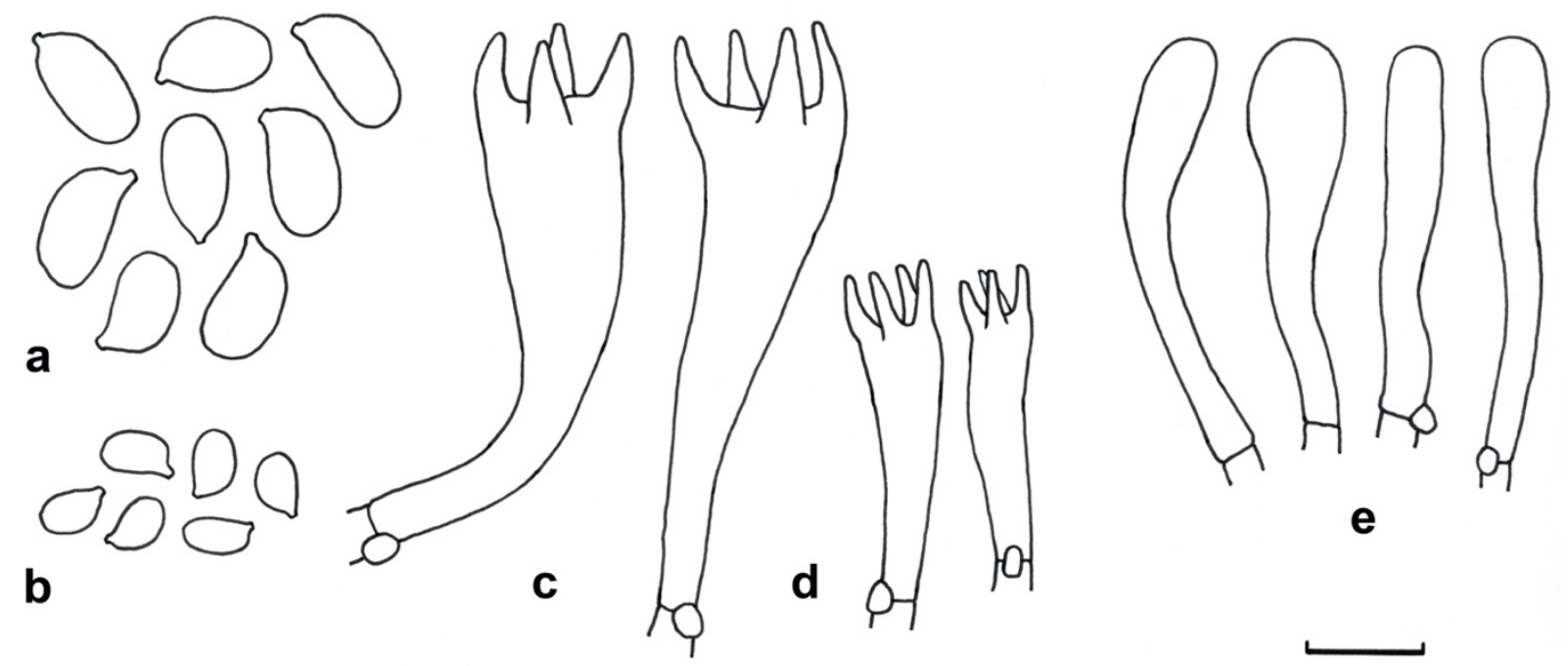

Fig. 5 - Micromorphological features of Hygrocybe macambrarensis (Holotype, BAP 597). a Macrospores. b Microspores. c Macrobasidia. d Microbasidia. e Cheilocystidia. Scale bar $=10$ $\mu \mathrm{m}$.

Hygrocybe aff. miniata (Fr.) P. Kumm., Führ. Pilzk. (Zerbst): 112. 1871.

Figs 6, 7a-c

Pileus 8-10 mm diam, convex to plano-convex, seldom shallowly depressed, non-striate; surface dull, moist to dry, smooth, glabrous, subhygrophanous, deep red (10C8), fading slightly with moisture loss. Context thin, concolorous with surface. Lamellae adnate with a short decurrent tooth, distant with 1 series of lamellulae, broad (1-1.5 mm), waxy, bases reddish orange (7B6-8), edges yellowish orange (4-5A5). Stipe 15-20 × 2.5-3 mm, central, terete, cylindrical or with a slightly enlarged base, brittle, hollow; surface dull, dry, glabrous; apex deep red (10C8), grading downward from reddish orange (7B6-8) to orange (5A5-6), base with white mycelium.

Basidiospores 11-13 × 6.0-7.5 $\mu \mathrm{m}\left[\mathrm{x}_{\mathrm{m}}=12.5 \pm 0.73 \times 7.1 \pm 0.6 \mu \mathrm{m}, \mathrm{Q}=1.6-2.0, \mathrm{Q}_{\mathrm{m}}=1.76\right.$ $\pm 0.12, \mathrm{n}=10, \mathrm{~s}=1]$, ellipsoid to obpyriform, smooth, hyaline, inamyloid, thin-walled. Basidia only one observed, $50 \times 9.5 \mu \mathrm{m}$, clavate, 4-spored. Basidioles 30-42 × 6.5-10 $\mu \mathrm{m}$, clavate. Lamellar edge sterile. Cheilocystidia 25-36 × 4-9 $\mu \mathrm{m}$, basidiole-like to irregularly cylindrical, 
sinuous or ventricose, hyaline, thin-walled. Pleurocystidia absent. Pileipellis a cutis of repent hyphae 3.5-10 mm diam, cylindrical, hyaline to pale yellow, inamyloid, non-incrusted, nongelatinous, thin-walled. Pileus trama interwoven; hyphae similar to pileipellis. Lamellar trama regular (parallel to subparallel); hyphae 3-10 $\mu \mathrm{m}$ diam, cylindrical, hyaline, inamyloid, nongelatinous, thin-walled. Stipitipellis a cutis, similar to pileipellis. Clamp connections present. Habitat and known distribution - Solitary in soil in native primary forest. Africa (Príncipe).

Material examined - Africa. Príncipe, south side of island at Rio São Tomé, N01³3'40.54", E07 21'15.51", 22 April 2008, coll. by B.A. Perry and D.E. Desjardin, DED 8311 (SFSU).

Notes - Distinctive features of Hygrocybe aff. miniata (DED 8311) include: small basidiomes with convex, deep red, glabrous pileus; adnate, yellowish orange lamellae; deep red to reddish orange stipe; ellipsoid to obpyriform basidiospores 11-13 $\times$ 6.0-7.5 $\mu \mathrm{m}$; monomorphic basidia; regular lamellar trama; a cutis-type pileipellis and stipitipellis; and solitary habit in soil in native forest. In combination, these features indicate placement in Hygrocybe sect. Coccineae subsect. Coccineae.

DED 8311 is morphologically similar to H. miniata (Fr.) P. Kumm. as reported from East Africa (Pegler 1977) and Sri Lanka (Pegler 1986), H. coccinea var. gracilis Heinem., described from DR Congo (Heinemann 1963), and H. substrangulata (P.D. Orton) P.D. Orton \& Watling and H. marchii (Bres.) F.H. Møeller from Europe (Arnold 1990, Boertmann 1995). H. miniata differs in forming a scurfy-fibrillose to squamulose pileus, and smaller basidiospores in the range 6-9 × 3.5$5.5 \mu \mathrm{m}$. $H$. coccinea var gracilis differs in having a pileus with crenate margin, shorter basidiospores $(7.8-9 \times 5.3-7.0 \mu \mathrm{m})$ and longer basidia $(60-75 \mu \mathrm{m})$. H. substrangulata forms larger basidiomes with finely squamulose, more orange pileus $5-50 \mathrm{~mm}$ diam, constricted basidiospores, and orangish yellow stipe. H. marchii forms smaller basidiospores $(6.5-8.5 \times 3.5-5.0 \mu \mathrm{m})$ and grows in grasslands. DED 8311 may represent the taxon reported by Beeli (1928) and Heinemann (1963) from the DR Congo as Hygrophorus cfr. miniatus Fr.

Due to the presence of numerous insertions/deletions in the ITS region, we were not able to successfully sequence this marker for collection DED 8311 and therefore have no pairwise genetic comparisons for this taxon.

\section{Hygrocybe sp. (DED 8297)}

Fig. 7d-e

Pileus $20 \mathrm{~mm}$ diam (single basidiome), convex, non-striate; surface dull, moist to dry, minutely squamulose, hygrophanous, red (10-11B7-8), fading slightly with moisture loss. Context 1-1.5 mm thick, red (10-11B8). Lamellae adnate with a decurrent tooth, distant with 1 series of lamellulae, broad $(-4 \mathrm{~mm})$, thick, waxy, dingy white with a hint of pink. Stipe $50 \times 4 \mathrm{~mm}$, central, terete, cylindrical, soft, pliant, hollow; surface dull, dry, glabrous, pink (10A4) to pale greyish pink (9B4), base with white strigose hairs. Basidiomes drying golden yellow to orange. Odor not distinctive.

Basidiospores 12.8-16 × 7-9.5 $\mu \mathrm{m}\left[\mathrm{x}_{\mathrm{m}}=14.1 \pm 1.01 \times 8.3 \pm 0.58 \mu \mathrm{m}, \mathrm{Q}=1.5-2.1, \mathrm{Q}_{\mathrm{m}}=\right.$ $1.71 \pm 0.25, \mathrm{n}=28, \mathrm{~s}=1$ ], ellipsoid, sometimes slightly constricted, smooth, hyaline, inamyloid, thin-walled. Basidia 50-60 × 13-17.3 $\mu \mathrm{m}$, clavate, 4-spored, sterigmata up to $10 \mu \mathrm{m}$ long. Basidioles clavate. Lamellar edge fertile. Cheilocystidia absent. Pleurocystidia absent. Pileipellis a trichodermium in squamulose areas, a cutis elsewhere, of repent to erect hyphae 8-16 $\mu \mathrm{m}$ diam, cylindrical to inflated, short-celled, hyaline, inamyloid, non-incrusted, non-gelatinous, thin-walled; terminal cells cylindrical to clavate, 10-18 $\mu \mathrm{m}$ diam. Pileus trama pseudoparenchymatous; hyphae inflated to vesiculose, up to $60 \mu \mathrm{m}$ diam. Lamellar trama subregular; hyphae 4.5-16 $\mu \mathrm{m}$ diam, cylindrical to inflated, short-celled, hyaline, non-gelatinous, thin-walled. Stipitipellis a cutis. Clamp connections present.

Habitat and known distribution - Solitary in soil in secondary forest. Africa (Príncipe).

Material examined - Africa. Príncipe, Roça Pico Papagaio, N0137.182', E07²3.474', 21 April 2008, coll. by D.E. Desjardin, DED 8297 (SFSU; MT117077). 


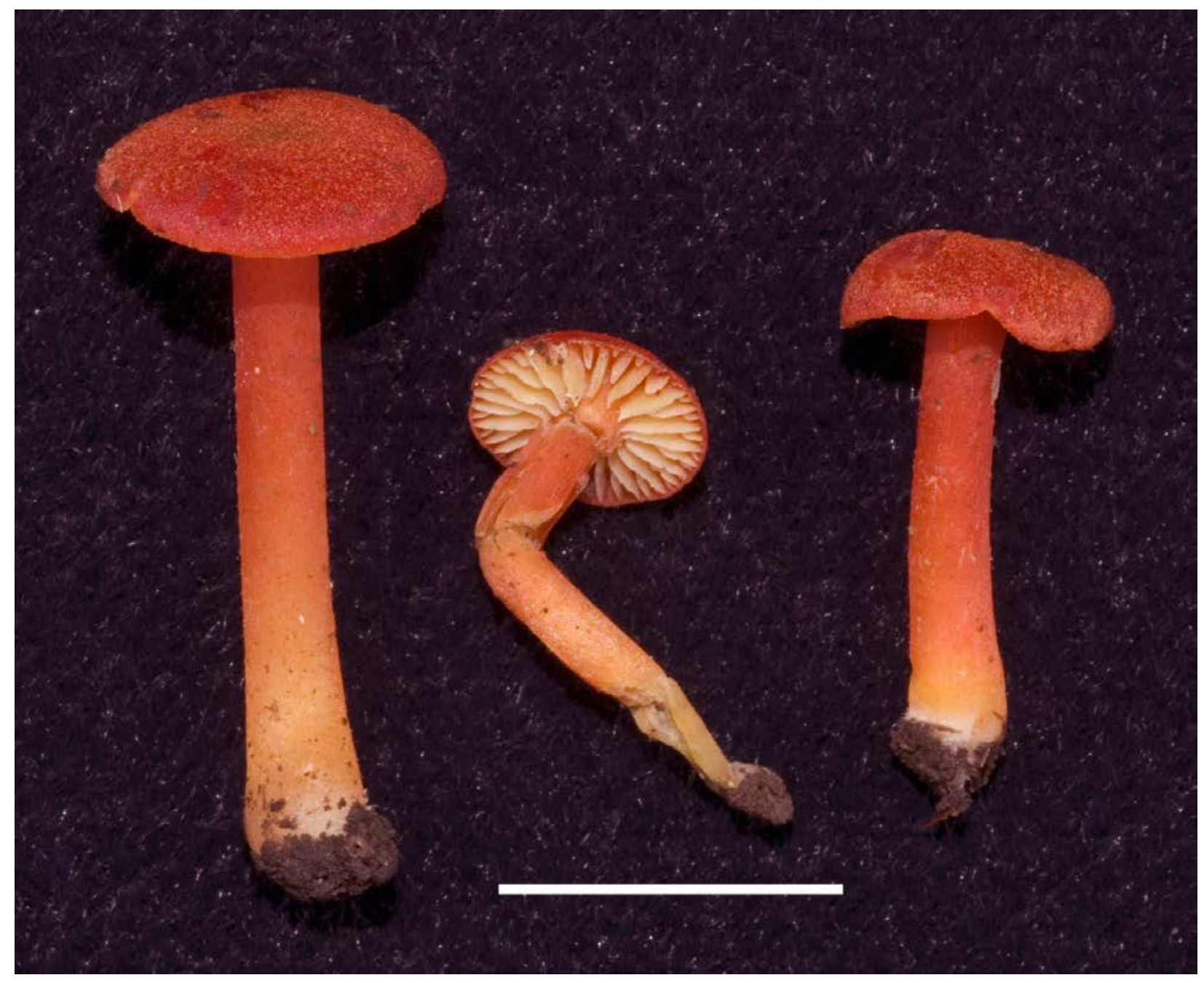

Fig. 6 - Basidiomes of Hygrocybe aff. miniata (DED 8311). Scale bar $=10 \mathrm{~mm}$.

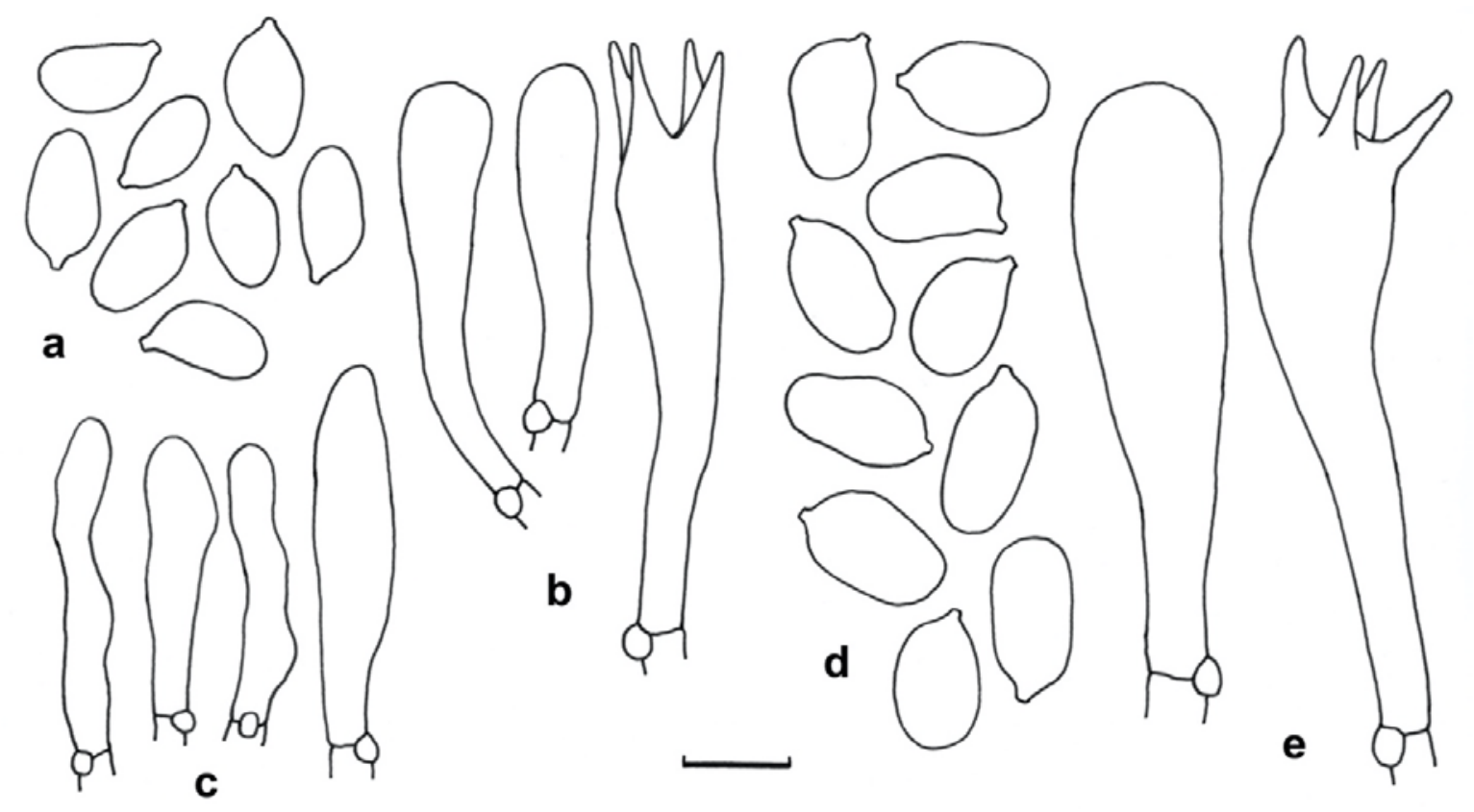

Fig. 7 - Micromorphological features of Hygrocybe species. a-c Hygrocybe aff. miniata (DED 8311). a Basidiospores. b Basidium and basidioles. c Cheilocystidia. d-e Hygrocybe sp. (DED 8297). $d$ Basidiospores. e Basidium and basidiole. Scale bars $=10 \mu \mathrm{m}$. 
Notes - Hygrocybe sp. (DED 8297) is characterized by a red, squamulose, convex pileus, pinkish white, adnate lamellae, a pink stipe, very large $(12.8-16 \times 7-9.5 \mu \mathrm{m})$, sometimes slightly constricted basidiospores, broad (13-17.3 $\mu \mathrm{m}$ diam), monomorphic basidia, a partial trichodermium-type pileipellis, subregular lamellar trama, and growth in secondary forest. In combination, these features indicate placement in Hygrocybe sect. Coccineae subsect. Squamulosae. The very large basidiospores of Hygrocybe sp. are not found in many other taxa in this taxonomic group. Most similar is H. appalachienensis (Hesler \& A.H. Sm.) Kronaw., with basidiospores 11-17.5 × 7-10 $\mu \mathrm{m}$, but it forms larger basidiomes with deeply depressed pileus 20$70 \mathrm{~mm}$ diam, decurrent lamellae with more orangish yellow tones, a red stipe 4-12 mm diam, and is reported with conspicuous pleurocystidia and cheilocystidia (Hesler \& Smith 1963). Also similar is H. substrangulata (P.D. Orton) P.D. Orton \& Watling, but it differs in a more reddish orange pileus, cream to yellowish orange lamellae, yellowish orange stipe, smaller basidiospores (9-12 ($14.5) \times 5-6.5(-8.5) \mu \mathrm{m})$, narrower basidia (8-10 $\mu \mathrm{m}$ diam), and grows in cold temperate habitats (Boertmann 1995, Candusso 1997).

Pairwise comparisons of aligned, overlapping ITS sequences of Hygrocybe sp. (DED 8297) with the top ten BLASTn results indicate closest similarity (79.6\%) with $\mathrm{H}$. miniata forma longipes from Massachusetts, USA (HM020677), $77.6 \%$ similarity with $H$. lucorum from England (EU784358), 76.7\% similarity with $H$. miniata from the United Kingdom, 76.5\% similarity with $H$. lepida from Mexico, and 76.2-76.9\% similarity with six sequences of uncultured fungal or Agaricales/Agaricomycetes clones from Michigan, Canada or Alaska (GU174396, FJ553227, FJ553722, FJ552821, FJ552696, KF618061). Although not one of the top ten BLASTn hits, comparison of DED 8297 with a sequence of the morphologically similar $H$. substrangulata shows 78.3\% similarity. This morphologically and molecularly distinct taxon from Príncipe, known from a single basidiome, will remain undetermined until more material is discovered.

\section{Key to Hygrophoroid Fungi of São Tomé and Príncipe}

1. Hymenophoral trama interwoven; pileus orange to light orange ...........................................2

1. Hymenophoral trama parallel to subparallel; pileus red ...............................................................

2. Basidiomes stout; pileus 20-55 mm diam; lamellae decurrent, 3-5 mm broad; stipe 25-45 × 3-9 $\mathrm{mm}$; basidiospores 4.5-5.5 $\mathrm{mm}$ diam, $\mathrm{Q}_{\mathrm{m}}=1.34$.....................................1. Cuphophyllus pratensis 2. Basidiomes gracile; pileus 4-15 (-25) mm diam; lamellae adnate to subdecurrent, 1-3 mm broad; stipe 10-28 $\times 1-3 \mathrm{~mm}$; basidiospores 3.5-4.5 $\mu \mathrm{m}$ diam, $\mathrm{Q}_{\mathrm{m}}=1.59$ 2. Cuphophyllus laranja

3. Basidia dimorphic, forming macrospores 9.6-12.5 × 5.6-7.0 $\mu \mathrm{m}$ and microspores 5.5-6.5 × 3.2$3.8 \mu \mathrm{m}$ 3. Hygrocybe macambrarensis

3. Basidia monomorphic, forming basidiospores in the range 11-16 × 6.0-9.5 $\mu \mathrm{m}$..... .4 4. Pileus 8-10 mm diam, glabrous; lamellae reddish orange to yellowish orange; stipe red to reddish orange; basidiospores $11-13 \times 6.0-7.5 \mu \mathrm{m}$

4. Hygrocybe aff. miniata 4. Pileus larger, up to $20 \mathrm{~mm}$ diam, minutely squamulose; lamellae white with a hint of pink; stipe pink to greyish pink; basidiospores 12.8-16 × 7-9.5 $\mu \mathrm{m}$ 5. Hygrocybe sp.

\section{Acknowledgments}

We thank Dr. Robert C. Drewes (California Academy of Sciences) who continues to initiate, coordinate and lead multi-organism biotic surveys on São Tomé and Príncipe; Eng. Arlindo de Ceita Carvalho, Director General of the Ministry of Environment, Victor Bonfim, Salvador Sousa Pontes and Danilo Barbero for permission to collect and export specimens for study. We are indebted to Société de Conservation et Développement for logistics and housing support, especially the wonderful staffs of Omali Lodge and Bom Bom Island. We are grateful for the support and cooperation of Bastien Loloumb of Zuntabawe and Faustino Oliviera, former Director of the botanical garden at Bom Sucesso. We were assisted in the field by Jose Ramos Maria Vital Pires on Príncipe and by Quintino Quade Cabral, Martinho Nascimiento and Jose Clara on São Tomé. For 
continuing support, we are most grateful to Ned Seligman, Quintino Quade Cabral and Roberta dos Santos of STePUP. We are grateful to the College of Science and Engineering at San Francisco State University for partial funding to support travel to São Tomé and Príncipe, and to the G. Lindsay Field Research Fund of the California Academy of Sciences (CAS) for financially supporting the expedition in 2006 and the Hagey Research Venture Fund (CAS) in 2008. Lastly, we are especially grateful to Roderick C.M. Hall, Coleman P. Burke and William K. Bowes Jr. whose generous philanthropy has supported our research on São Tomé and Príncipe.

\section{References}

Altschul SF, Gish W, Miller W, Myers EW, Lipman DJ. 1990 - Basic local alignment search tool. Journal of Molecular Biology 215, 403-410.

Arnold E. 1990 - Tribus Hygrocybeae. In: Bas C, Kuyper TH, Noordeloos ME, Vellinga EC, eds. Flora Agaricina Neerlandica 2, 70-111.

Beeli M. 1928 - Contribution a l'étude de la flore mycologique du Congo. VI. Fungi Goossensiani. Belgian Journal of Botany 61(1), 78-107.

Boertmann D. 1995 - The genus Hygrocybe. Fungi of Northern Europe 1, 1-184.

Boertmann D. 1998 - A new species of Hygrocybe (Agaricales) from KwaZulu-Natal, South Africa. South African journal of Botany 64(3), 178-181.

Candusso M. 1997 - Fungi Europaei 6. Hygrophorus s.l. Libreria Basso, Alassio. 784 p.

Cantrell SA, Lodge DJ. 2001 - Hygrophoraceae (Agaricales) of the Greater Antilles: Hygrocybe subgenus Pseudohygrocybe section Firmae. Mycological Research 105(2), 215-224.

Cooper AC, Desjardin DE, Perry BA. 2018 - The genus Mycena (Basidiomycota, Agaricales, Mycenaceae) and allied genera from Republic of São Tomé and Príncipe, West Africa. Phytotaxa 383(1), 1-47.

Desjardin DE, Perry BA. 2009 - A new species of Phallus from São Tomé, Africa. Mycologia 101(4), 543-545.

Desjardin DE, Perry BA. 2015a - A new species of Scytinopogon from the island of Príncipe, Republic of São Tomé and Príncipe, West Africa. Mycosphere 6(4), 433-440.

Desjardin DE, Perry BA. 2015b - Clavarioid fungi and Gasteromycetes from the Republic of São Tomé and Príncipe, West Africa. Mycosphere 6(4), 515-531.

Desjardin DE, Perry BA. 2016 - Dark-spored species of Agaricineae from Republic of São Tomé and Príncipe, West Africa. Mycosphere 7(3), 359-391.

Desjardin DE, Perry BA. 2017 - The gymnopoid fungi (Basidiomycota, Agaricineae) from the Republic of São Tomé and Príncipe, West Africa. Mycosphere 8(9), 1317-1391.

Gardes M, Bruns TD. 1993 - ITS primers with enhanced specificity for basidiomycetes application to the identification of mycorrhizae and rusts. Molecular Ecology 2, 113-118.

Heinemann P. 1963 - Champignons récoltés au Congo par Madame M. Goossens-Fontana v. Hygrophoraceae. Bull. Jard. Bot. Etat Bruxelles 33(4), 421-458.

Hesler LR, Smith AH. 1963 - North American Species of Hygrophorus. University of Tennessee Press, Knoxville, Tennessee. p. 416.

Kornerup A, Wanscher JH. 1978 - Methuen Handbook of Colour. 3rd ed. Eyre Methuen, London.

Lodge DJ, Pegler DN 1990 - Hygrophoraceae of the Luquillo Mountains of Puerto Rico. Mycological Research 94(4), 443-456.

Lodge DJ, Padamsee M, Matheny PB, Aime MC et al. 2013 - Molecular phylogeny, morphology, pigment chemistry and ecology in Hygrophoraceae (Agaricales). Fungal Diversity 64, 1-99.

Pegler DN. 1986 - Agaric flora of Sri Lanka. Kew Bulletin Additional Series 12, 1-519.

Pegler DN. 1977 - A preliminary agaric flora of East Africa. Kew Bulletin Additional Series 6, 1615.

Pegler DN, Fiard JP. 1978 - Hygrocybe sect. Firmae (Agaricales) in tropical America. Kew Bulletin 32(2), 297-312. 
Perry BA, Hansen K, Pfister DH. 2007 - A phylogenetic overview of the family Pyronemataceae (Ascomycota, Pezizales). Mycological Research 111, 549-571.

Senthilarasu G, Kumaresan V, Singh SK. 2010a - A new species of Hygrocybe in section Firmae from Western Ghats, India. Mycotaxon 111, 301-307.

Senthilarasu G, Kumaresan V, Singh SK. 2010b - Hygrocybe manadukaensis sp. nov. in section Firmae from Western Ghats, India. Mycotaxon 114, 343-349.

van der Westhuizen GCA, Eicker A. 1994 - Mushrooms of Southern Africa. Struik Publishers, Inc., Cape Town, South Africa. 207 p.

Vizzini A, Picciola P, Battistin E, Ercole E. 2015 - Hygrocybe rubroalba (Hygrophoraceae, Agaricales), a new species of sect. Firmae from Brazil. Phytotaxa 226(1), 18-26.

White TJ, Bruns T, Lee S, Taylor J. 1990 - Amplification and direct sequencing of fungal ribosomal RNA genes for phylogenetics. In: Innis MA, Gelfand DH, Sninsky JJ, White TJ, eds. PCR Protocols: a guide to methods and applications. San Diego: Academic Press. p. 315-322. 